\title{
Carbon-Fluorine Reductive Elimination from a High-Valent Palladium Fluoride
}

\section{Citation}

Furuya, Takeru, and Tobias Ritter. 2008. Carbon-fluorine reductive elimination from a highvalent palladium fluoride. Journal of the American Chemical Society 130(31): 10060-10061.

\section{Published Version}

doi:10.1021/ja803187x

\section{Permanent link}

http://nrs.harvard.edu/urn-3:HUL.InstRepos:8156531

\section{Terms of Use}

This article was downloaded from Harvard University's DASH repository, and is made available under the terms and conditions applicable to Open Access Policy Articles, as set forth at http:// nrs.harvard.edu/urn-3:HUL.InstRepos:dash.current.terms-of-use\#OAP

\section{Share Your Story}

The Harvard community has made this article openly available.

Please share how this access benefits you. Submit a story.

Accessibility 


\title{
Carbon-Fluorine Reductive Elimination from a High-Valent Palladium Fluoride
}

\author{
Takeru Furuya and Tobias Ritter* \\ Department of Chemistry and Chemical Biology, Harvard University, 12 Oxford Street, Cambridge, MA \\ RECEIVED DATE; ritter@chemistry.harvard.edu
}

Aryl fluorides are valuable compounds as pharmaceuticals ${ }^{1}$ and as tracers for positron-emission tomography. ${ }^{2}$ The general synthesis of complex, highly functionalized aryl fluorides in which the carbon-fluorine bond is introduced at a late stage of the synthesis is a challenge unmet by conventional fluorination methods. We recently communicated that aryl boronic acids can be converted into aryl fluorides via reaction of stoichiometric aryl palladium complexes with the electrophilic fluorination reagent Selectfluor ${ }^{\text {TM }} 3$ (1) (eq 1). ${ }^{4}$ Two potential mechanisms for carbonfluorine bond formation are palladium-carbon bond cleavage by the electrophilic fluorination reagent and oxidation of the palladium center to form a discrete high-valent palladium fluoride followed by reductive elimination to form a carbon-fluorine bond. In this communication we present the carbon-fluorine bond formation from two high-valent aryl palladium fluoride complexes. The observation of high-valent palladium fluorides may afford valuable mechanistic insight to better understand carbon-fluorine bond formation mediated by transition metals.

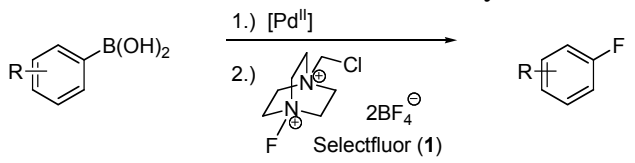

Transition-metal-mediated carbon-fluorine bond formations are rare. ${ }^{5}$ Three processes, including our own work, ${ }^{4}$ have been reported using palladium complexes and electrophilic fluorination sources. In 2006, Sanford published a palladium catalyzed fluorination of phenylpyridine derivatives and related substrates in which carbon-hydrogen bonds proximal to the pyridine directing group were fluorinated (microwave, $100-150{ }^{\circ} \mathrm{C}, 1-4 \mathrm{~h}, 33-75 \%$ yield). ${ }^{6} \quad$ Vigalok reported in 2008 the formation of 1,4difluorobenzene and 4-fluoroiodobenzene in $10 \%$ and $90 \%$ yield, respectively, from an aryl-iodo-bisphosphine palladium (II) complex upon treatment with 1-fluoro-2,4,6-trimethylpyridinium tetrafluoroborate. $^{7}$ For all three processes, the intermediacy of a high-valent palladium fluoride followed by reductive elimination to form the carbon-fluorine bond and a palladium (II) complex was discussed as a potential reaction pathway. In none of the cases, however, was a high-valent palladium intermediate characterized or observed. In fact, a carbon-fluorine bond formation to form an aryl fluoride by concerted aryl-fluorine reductive elimination from a well-defined transition metal fluoride, while implicated ${ }^{8}$ has not been substantiated in the literature from any transition metal in any oxidation state. ${ }^{8,9}$

Scheme 1 shows a reaction sequence to convert a boronic acid into the corresponding arylfluoride. We found that pyridylsulfonamide ligands such as $\mathbf{2}$ are well suited for the fluorination reaction, because they serve as ancillary ligands to support arylpalladium complexes such as $\mathbf{5}$, which afford arylfluorides regiospecifically upon treatment with Selectfluor ${ }^{\mathrm{TM}}$ in high yield ( $87 \%$ in the presented case). The palladium (II) acetate complex 3 was obtained in $99 \%$ yield from pyridyl-sulfonamide 2 and palladium (II) acetate in the presence of three equivalents of pyridine. Transmetallation using 4-tert-butylphenylboronic acid (4) afforded the air- and water-stable yellow aryl palladium complex 5 in $80 \%$ yield. Fluorination of $\mathbf{5}$ with Selectfluor ${ }^{\mathrm{TM}}$ in acetone at $50{ }^{\circ} \mathrm{C}$ gave 4 -tert-butylfluorobenzene (6) in $87 \%$ yield within $30 \mathrm{~min}$.

Scheme 1. Fluorination of arylboronic acids via stoichiometric arylpalladium complexes using Selectfluor ${ }^{\mathrm{TM}}$.

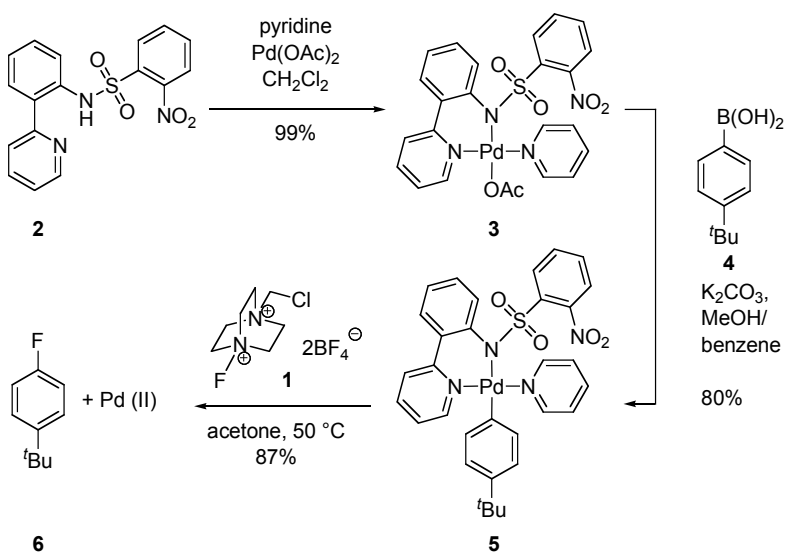

Under the reaction conditions that afforded $87 \%$ yield of $\mathbf{6}$ (acetone, $50{ }^{\circ} \mathrm{C}$ ), we did not observe a high-valent palladium fluoride intermediate by NMR, but a reversible color change from yellow to orange upon addition of 5 to Selectfluor ${ }^{\mathrm{TM}}$ suggested the formation of a discrete intermediate. To evaluate the mechanistic hypothesis that pyridyl-sulfonamide-stabilized aryl palladium complexes such as $\mathbf{5}$ can afford carbon-fluorine bond formation via well-defined discrete palladium fluorides, we sought to design an analog of $\mathbf{5}$ that would afford an observable palladium (IV) fluoride upon oxidation with Selectfluor ${ }^{\mathrm{TM}}$. Rigid ligands have been shown to stabilize high-valent metal centers including palladium (IV). ${ }^{10}$ We therefore synthesized the palladium (II) derivative $\mathbf{8}$, in which a rigid, chelating benzoquinolinyl ligand substitutes the aryl and pyridyl ligands of 5 (eq 2). Treatment of the benzoquinolinyl palladium acetate dimer $7^{11}$ with one equivalent of the pyridyl-sulfonamide ligand 2 in methylene chloride at room temperature afforded the aryl palladium complex $\mathbf{8}$ in $95 \%$ yield as an analytically pure yellow solid within $20 \mathrm{~min}$.

Fluorination of $\mathbf{8}$ in acetonitrile at $50{ }^{\circ} \mathrm{C}$ afforded 10 fluorobenzo[h]quinoline (10) in 94\% yield (Scheme 2). Moreover, we observed a deep purple, well-defined intermediate by ${ }^{1} \mathrm{H}$ and ${ }^{13} \mathrm{C} \mathrm{NMR}$, which was not contaminated with either 8 or 10 and had a half-life of ca. 70 minutes in acetonitrile solution at $23{ }^{\circ} \mathrm{C} .{ }^{12}$ The NMR resonances, including an ${ }^{19} \mathrm{~F}$ NMR resonance at $-278 \mathrm{ppm}$, are consistent with the terminal palladium (IV) fluoride 9; the instability of $\mathbf{9}$ precluded isolation and purification for additional characterization. When the acetonitrile solution of 9 was subsequently heated to $50{ }^{\circ} \mathrm{C}$, reductive elimination 


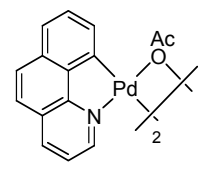

7

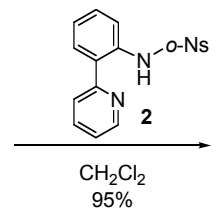

$95 \%$

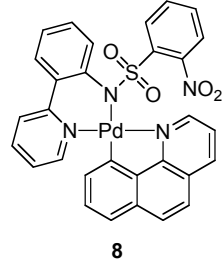

occurred to form 10. Additional evidence for the formation of a high-valent palladium fluoride was obtained, when the intermediate 9 was treated with tetramethylammonium fluoride tetrahydrate at room temperature to form the palladium (IV) difluoride $\mathbf{1 1}$ that we independently synthesized by oxidation of $\mathbf{8}$ with $\mathrm{XeF}_{2}$.

Scheme 2. Carbon-fluorine bond formation by reductive elimination.
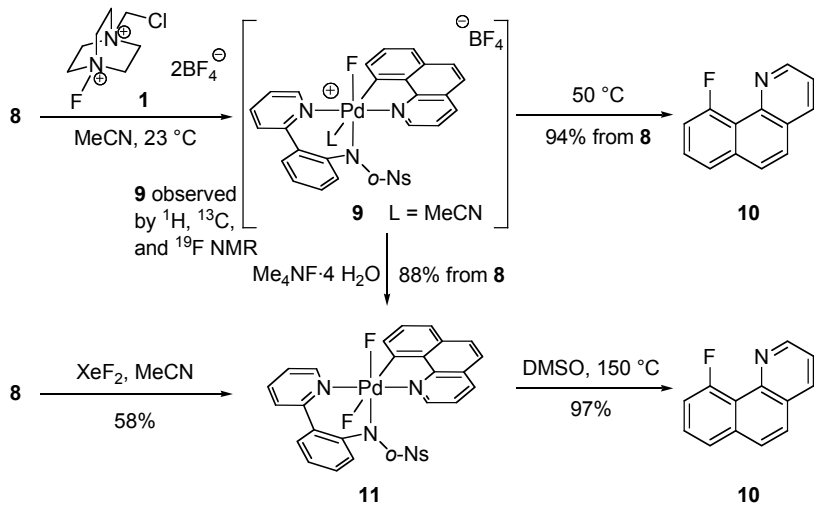

Reductive elimination from 9 afforded a cationic palladium (II) tetrafluoroborate that was trapped with pyridine to afford the cationic palladium bispyridine tetrafluoroborate $\mathbf{1 2}$, which was observed by NMR and mass spectrometry in the reaction mixture, and independently synthesized from the palladium acetate $\mathbf{3}$ in 94\% yield (Scheme 3). The isolation of 12 with the pyridylsulfonamide ligand coordinated to palladium is consistent with a reductive elimination from 9 .

Scheme 3. Independent synthesis of the cationic palladium tetrafluoroborate 12 .

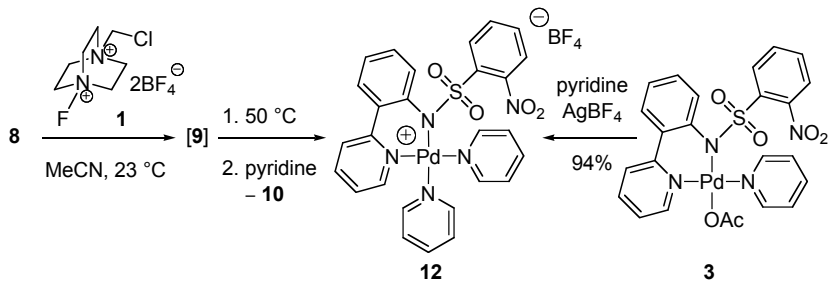

The neutral palladium difluoride $\mathbf{1 1}$ was thermally more stable than the monofluoride 9, could be isolated, and afforded $\mathbf{1 0}$ in $97 \%$ yield when heated in DMSO at $150{ }^{\circ} \mathrm{C}$ for 10 minutes (Scheme 2). The increased thermal stability of $\mathbf{1 1}$ when compared to $\mathbf{9}$ is consistent with the formation of a penta-coordinated palladium (IV) fluoride prior to reductive elimination. ${ }^{13}$ The palladium (IV) difluoride $\mathbf{1 1}$ is an air and moisture stable bright orange solid that is stable at $23{ }^{\circ} \mathrm{C}$ for at least 1 week and in chloroform solution at $50{ }^{\circ} \mathrm{C}$ for at least 2 hours. $\mathrm{A}^{2} J_{\mathrm{F}-\mathrm{F}}$ coupling constant of $113 \mathrm{~Hz}$ indicates that both fluorine atoms are associated with the palladium atom in solution. The palladium (IV) difluoride crystallized from an acetonitrile solution as orange prisms and was analyzed by X-ray crystallography (Figure 1). The two fluoride substituents are mutually cis and have bond

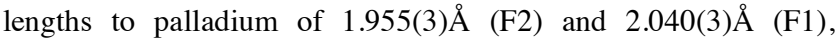

respectively. To our knowledge, a high-valent organometallic palladium difluoride has not been reported previously.

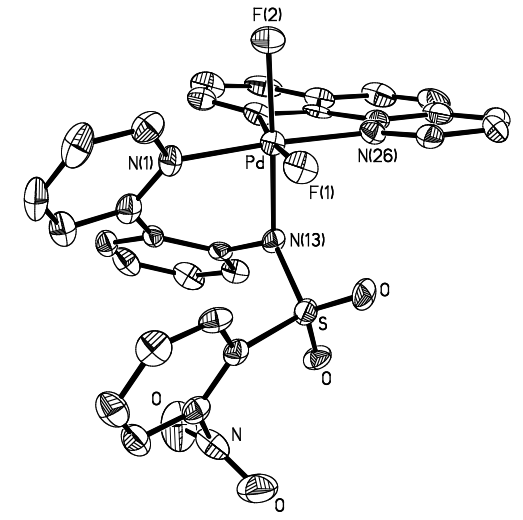

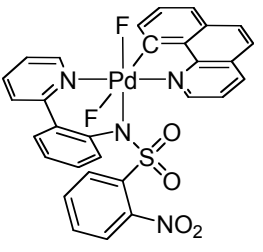

11

${ }^{19} \mathrm{~F} \mathrm{NMR}^{14}:-169,-278$ ppm; ${ }^{2} J_{\mathrm{F}-\mathrm{F}}=113 \mathrm{~Hz}$

${ }^{2} J_{\mathrm{C}-\mathrm{F}}=63 \mathrm{~Hz}$
Figure 1. ORTEP drawing of the palladium (IV) difluoride $\mathbf{1 1}$ with $50 \%$ probability ellipsoids (hydrogen atoms and solvent omitted for clarity). Selected bond lengths $[\AA]$ and angles $\left[{ }^{\circ}\right]$ : $\quad \mathrm{Pd}-\mathrm{F}(1) 2.040(3), \mathrm{Pd}-\mathrm{F}(2)$ 1.955(3), Pd-C(35) 2.008(5), Pd-N(13) 2.019(4), Pd-N(1) 2.027(5), Pd$\mathrm{N}(26) 2.012(5), \mathrm{F}(1)-\mathrm{Pd}-\mathrm{F}(2) 88.27(13), \mathrm{F}(2)-\mathrm{Pd}-\mathrm{N}(13) 173.48(15)$

In conclusion we have shown carbon-fluorine bond formation from two discrete palladium (IV) fluoride complexes. Our data is consistent with a well-defined reductive elimination and provides insight into carbon-fluorine bond formation from arylpalladium complexes.

Acknowledgement. We thank Dr. Shaw Huang for NMR analysis, Dr. Imhyuck Bae and Christian Kuttruff for discussions, Merck \& Co. and Amgen Inc. for unrestricted support, Eli Lilly for a graduate fellowship for T.F., and Dr. Douglas M. Ho and Jessica Y. Wu for X-ray crystallographic analysis.

Supporting Information Available: Detailed experimental procedures and spectroscopic data for all new compounds as well as crystallographic analysis of 11. This material is available free of charge via the Internet at http://pubs.acs.org.

\section{REFERENCES}

(1) Müller, K. Faeh, C.; Diederich, F. Science 2007, 317, 1881-1886.

(2) Phelps, M. E. Proc. Natl. Acad.Sci.U.S. A. 2000, 97, 9226-9233.

(3) Singh, R. P.; Shreeve, J. M. Acc. Chem. Res. 2004, 37, 31-44.

(4) Furuya, T.; Kaiser, H. M.; Ritter, T. Angew. Chem., Int. Ed. 2008, in press.

(5) (a) For a recent review on metal-mediated C-halogen bond formation, see: Vigalok, A. Chem.-Eur. J. 2008, 14, 5102-5108. (b) For a C-Cl bond formation from Pd (IV), see: Whitfield, S. R.; Sanford, M. S. J. Am. Chem. Soc. 2007, 129, 15142-15143. (c) For C-F bond formation mediated by $\mathrm{Cu}$, see: Subramanian, M. A.; Manzer, L. E. Science, 2002, 297, 1665. (d) Grushin, V. U.S. Patent 7,202,388, 2007. For oxidative addition of C-F bonds to Pd, see for example: (e) Yu, S.; Mi, Y. J. Am. Chem. Soc. 2003, 125, 1696-1697; (f) Dankwardt, J. W. J. Organomet. Chem. 2005, 690, 932-938.

(6) Hull, K. L.; Anani, W. Q.; Sanford, M. S. J. Am. Chem. Soc. 2006, 128 7134-7135.

(7) Kaspi, A. W.; Yahav-Levi, A.; Goldberg, I.; Vigalok, A. Inorg. Chem 2008, 47, 5-7.

(8) Yandulov, D. V.; Tran, N. T. J. Am. Chem. Soc. 2007, 129, 1342-1358

(9) (a) Grushin, V. V. Chem.-Eur. J. 2002, 8, 1006-1014; (b); Grushin, V. V.; Marshall, W. J. Organometallics 2007, 26, 4997-5002.

(10) (a) Canty, J. A. Acc. Chem. Res. 1992, 25, 83-90; (b) Canty, A. J.; Jin, H.; Roberts, A. S.; Skelton, B. W.; Traill, P. R.; White, A. H. Organometallics 1995, 14, 199-206; (c) Canty, A. J.; Denney, M. C.; van Koten, G.; Skelton, B. W.; White, A. H. Organometallics 2004, 23, 5432-5439; (d) Campora, J.; Palma, P.; del Rio, D.; Lopez, J. A.; Alvarez, E.; Connelly, N. G. Organometallics 2005, 24, 3624-3628; (e) Dick, A. R.; Kampf, J. W.; Sanford, M. S. J. Am. Chem. Soc. 2005, 127, 12790-12791.

(11) Dick, A. R.; Hull, K. L.; Sanford, M. S. J. Am. Chem. Soc. 2004, 126 , 2300-2301.

(12) At $23{ }^{\circ} \mathrm{C}, \mathbf{1 0}$ was formed from 9 in $73 \%$ yield over 18 hours.

(13) Byers, P. K.; Canty, A. J.; Crespo, M.; Puddephat, R. J.; Scott, J. D. Organometallics 1988, 7, 1363-1367. 
(14) For comparison of the ${ }^{19} \mathrm{~F}$ chemical shifts to other Pd (II), Pt (II), and Pt (IV) fluorides, see Supporting Information. 


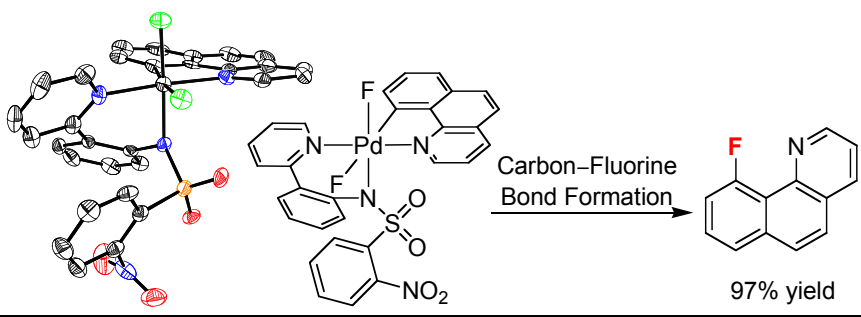

We have observed two high-valent arylpalladiumfluoride complexes that afford carbon-fluorine bond formation upon thermolysis. 